\title{
Living without lungs? Bilateral pneumonectomy and dual circulatory support: A step forward in the search for a total artificial lung
}

\author{
Christian A. Bermudez, MD, ${ }^{a}$ and Maria M. Crespo, MD $^{\mathrm{b}}$
}

\author{
From the Divisions of ${ }^{\mathrm{a}}$ Cardiovascular Surgery and ${ }^{\mathrm{b}}$ Pulmonary, Allergy and Critical Care, University of Penn- \\ sylvania Health System, Philadelphia, Pa. \\ Disclosures: Authors have nothing to disclose with regard to commercial support. \\ Received for publication Jan 20, 2017; accepted for publication Jan 28, 2017. \\ Address for reprints: Christian A. Bermudez, MD, Division of Cardiovascular Surgery, Hospital of the University \\ of Pennsylvania, 3400 Spruce St, 6th Floor Silverstein, Philadelphia, PA 19104 (E-mail: christian.bermudez@ \\ uphs.upenn.edu). \\ J Thorac Cardiovasc Surg 2017;153:e71-2 \\ $0022-5223 / \$ 36.00$ \\ Copyright (c) 2017 by The American Association for Thoracic Surgery \\ http://dx.doi.org/10.1016/j.jtcvs.2017.01.035
}

In this issue of the Journal, Cypel and colleagues ${ }^{1}$ describe the first case of combination support with central venoarterial (VA) extracorporeal membrane oxygenation (ECMO) and a pumpless Novalung (Xenios, Heilbronn, Germany) device, placed from the pulmonary artery (PA) to the left atrium (LA), to allow bilateral pneumonectomy, stabilization, and lung transplantation 6 days after initiation of support with a successful outcome in a patient with cystic fibrosis in septic shock driven by pulmonary infection. We wish to highlight 2 concepts presented in this innovative and provocative report: (1) the efficacy of bilateral pneumonectomy in controlling active pulmonary sepsis and (2) the successful circulatory and respiratory support provided by a dual system including central VA-ECMO and a central, pumpless Novalung.

Patients with cystic fibrosis who develop pulmonary failure requiring lung transplantation often present with drugresistant infections, rapid decompensation, and a need for mechanical ventilation. ${ }^{2,3}$ ECMO can be used as a bridge to lung transplant. ${ }^{4,5}$ Pulmonary infections, however, can exclude patients from consideration for lung transplantation, because of high perioperative mortality, and rapidly lead to multiorgan failure and death. Until recently, bilateral pneumonectomy only could be considered during the lung transplant procedure with the use of full circulatory support, typically cardiopulmonary bypass, to maintain hemodynamic and respiratory stability in the absence of circulation to the left cardiac structures. Concerns of prolonged VA-ECMO in the setting of bilateral pneumonectomy include right ventricular dilatation and intracardiac and intravascular thrombosis secondary to an inadequate drainage of the right ventricle, proximal PAs, and LA. The potential for inadequate drainage of the cardiac and vascular structures when standard VA-ECMO was used limited interest in maintaining patients for prolonged periods without pulmonary circulation.

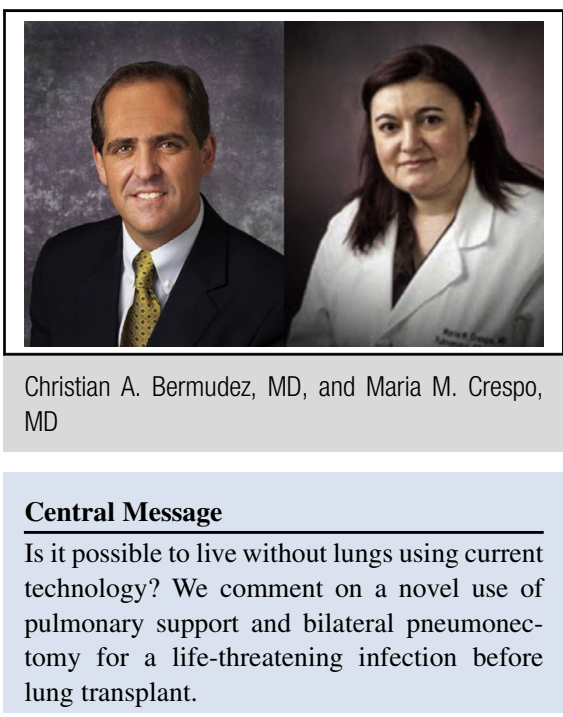

See Article page e67.

Despite these concerns, the authors' audacious decision to perform a bilateral pneumonectomy was based on the inability to oxygenate the patient on venovenous ECMO and her uncontrolled pulmonary sepsis. The authors carefully planned the procedure, leaving sufficient vascular and bronchial structures to allow subsequent allograft implantation. This concept could be applied to other lung diseases associated with infectious complications, and a comprehensive analysis of bilateral pneumonectomy as a mechanism to control infection in specialized circumstances is warranted.

The second and probably most stimulating concept presented in this case report is that a combination of devices can provide prolonged circulatory and respiratory support in the absence of lung parenchyma, acting as a total artificial lung. Based on their previous experience with ECMO and with the Novalung pumpless, low-gradient, membrane oxygenator, the authors placed the Novalung from the right PA to the LA, similar to the configuration they used to support patients with severe pulmonary hypertension as a bridge to lung transplantation. ${ }^{4-9}$ With this combination of support and maintaining a balanced flow on both devices, they were able to obtain adequate drainage of the right cardiac structures while allowing adequate filling of the left side of the heart, preventing right ventricular dilatation and intravascular thrombosis. Their 
ingenious and effective approach proves an important concept: It is possible to live without lungs for a prolonged period by using current technologies!

As specialists in this field, we are excited to see future developments in total lung replacement and mechanical support and can only dream of the potential applications of a totally artificial lung in end-stage lung disease and lung transplantation. We congratulate the Toronto team for their brave attempts to explore the unknown in the era of outcomes and evidence-based medicine.

\section{References}

1. Cypel M, Waddell T, Singer L, Del Sorbo L, Fan E, Binnie M, et al. Bilateral pneumonectomies to treat uncontrolled sepsis in a patient awaiting lung transplantation. J Thorac Cardiovasc Surg. 2017; 153:e67-9.

2. Chaparro C, Keshavjee S. Lung transplantation for cystic fibrosis: an update. Expert Rev Respir Med. 2016;10:1269-80.
3. Lynch JP III, Sayah DM, Belperio JA, Weigt SS. Lung transplantation for cystic fibrosis: results, indications, complications, and controversies. Semin Respir Crit Care Med. 2015;36:299-320.

4. Bermudez CA, Rocha RV, Sappington PL, Toyoda Y, Murray HN, Boujoukos AJ. Initial experience with single cannulation for venous-venous extracorporeal oxygenation in adults. Ann Thorac Surg. 2010;90:991-5.

5. Toyoda Y, Bhama JK, Shigemura N, Zaldonis D, Pilewski J, Crespo M, et al. Efficacy of extracorporeal membrane oxygenation as a bridge to lung transplantation. J Thorac Cardiovasc Surg. 2013;145:1065-71.

6. Cypel M, Keshavjee S. Extracorporeal life support as a bridge to lung transplantation. Clin Chest Med. 2011;32:245-51.

7. De Perrot M, Granton JT, McRae K, Cypel M, Pierre A, Waddell TK, et al. Impact of extracorporeal life support on outcome in patients with idiopathic pulmonary arterial hypertension awaiting lung transplantation. J Heart Lung Transplant. 2011;30:997-1002.

8. Hill JD, O'Brien TG, Murray JJ, Dontigny L, Bramson ML, Osborn JJ, et al. Prolonged extracorporeal oxygenation for acute post-traumatic respiratory failure (shock-lung syndrome). Use of the Bramson membrane lung. $N$ Engl J Med. 1972;286:629-34.

9. McCarthy FH, McDermott KM, Kini V, Gutsche JT, Wald JW, Xie D, et al. Trends in U.S. extracorporeal membrane oxygenation use and outcomes: 2001-2012. Semin Thorac Cardiovasc Surg. 2015;27:81-8. 